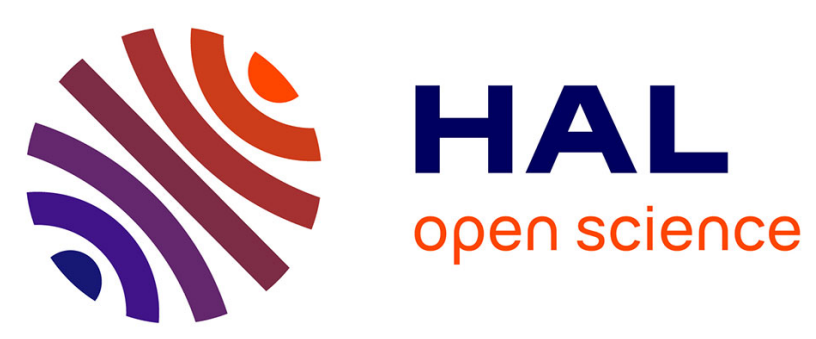

\title{
Nanoscale conversion of chlorapatite into hydroxyapatite using ultrasound irradiation
}

\author{
Habiba Bouyarmane, Asmae Gouza, Sylvie Masse, Sanaa Saoiabi, Ahmed \\ Saoiabi, Thibaud Coradin, Abdelaziz Laghzizil
}

\section{- To cite this version:}

Habiba Bouyarmane, Asmae Gouza, Sylvie Masse, Sanaa Saoiabi, Ahmed Saoiabi, et al.. Nanoscale conversion of chlorapatite into hydroxyapatite using ultrasound irradiation. Colloids and Surfaces A: Physicochemical and Engineering Aspects, 2016, 495, pp.187-192. 10.1016/j.colsurfa.2016.02.014 . hal-01276315

\section{HAL Id: hal-01276315 https://hal.sorbonne-universite.fr/hal-01276315}

Submitted on 19 Feb 2016

HAL is a multi-disciplinary open access archive for the deposit and dissemination of scientific research documents, whether they are published or not. The documents may come from teaching and research institutions in France or abroad, or from public or private research centers.
L'archive ouverte pluridisciplinaire HAL, est destinée au dépôt et à la diffusion de documents scientifiques de niveau recherche, publiés ou non, émanant des établissements d'enseignement et de recherche français ou étrangers, des laboratoires publics ou privés. 


\section{Nanoscale conversion of chlorapatite into hydroxyapatite using ultrasound irradiation}

Habiba Bouyarmane, ${ }^{a}$ Asmae Gouza, ${ }^{a}$ Sylvie Masse, Sanaa Saoiabi, ${ }^{\text {a }}$ Ahmed Saoiabi, Thibaud Coradin,, ,"* $^{*}$ Abdelaziz Laghzizil ${ }^{\mathrm{a}, *}$

${ }^{a}$ Laboratoire de Chimie Physique Générale, Université Mohammed V, Faculté des Sciences BP.1014 Rabat, Morocco.

${ }^{b}$ Sorbonne Universités, UPMC Univ Paris 06, CNRS, UMR 7574, Laboratoire de Chimie de la Matière Condensée de Paris, F-75005 Paris, France.

\section{*Corresponding authors :}

T. Coradin ; e-mail : thibaud.coradin@upmc.fr; tel : 33-144271528 ; fax :33-144274769

A. Laghzizil ; e-mail : laghzizi@fsr.ac.ma; tel/fax : 212-537775440 


\begin{abstract}
The ultrasound-assisted conversion of chlorapatite nanoparticles obtained from a natural phosphate rock into hydroxyapatite nanocrystals was achieved within one hour. The process had no significant impact on particle crystallinity but led to a significant decrease of the colloidal size. Similar variations were obtained for hydroxyapatite nanoparticles treated in the same conditions, suggesting that these variations are not due to the compositional modification. Analyses of the solubility properties of the two phases and of the ionic contents of the reaction medium suggest that the undersaturated conditions of the reaction and the cavitation phenomena favor surface exchange and erosion mechanisms over bulk amorphization .
\end{abstract}

Keywords : hydroxyapatite ; sonochemistry; topotactic conversion; nanomaterials 


\section{1. introduction}

Natural phosphates are one of the major reservoirs of both phosphorus and calcium in the Earth's crust [1]. Fluoroapatite $\left(\mathrm{Ca}_{10}\left(\mathrm{PO}_{4}\right)_{6} \mathrm{~F}_{2}\right)$, and its carbonated form francolite, is the main component of Moroccan natural phosphates [2-4]. Among other applications, the cationexchange properties of phosphocalcic apatites as well as their rich surface chemistry make them valuable materials as sorbents for water remediation [5-8]. However, natural apatites exhibit low specific areas that limit their sorption capacity [9-11]. Therefore many physical and chemical routes have been developed to obtain phosphocalcic apatites as high surface area powders from inorganic salts [12]. Of particular interest here are sonochemistry routes that allow control of the particle size and crystallinity through the modulation of irradiation power and duration [13-21]. As a more sustainable alternative, a process allowing for the conversion of natural phosphate into porous hydroxyapatite $\left(\mathrm{Ca}_{10}\left(\mathrm{PO}_{4}\right)_{6}(\mathrm{OH})_{2}\right)$ was recently described $[22,23]$. The procedure involves the dissolution of the natural ore in nitric acid, filtration of the remaining minerals (mainly quartz) and reprecipitation by neutralization.

Although this approach has the benefits of using raw materials available in large quantity and being performed in purely aqueous conditions, the use of nitric acid at a large scale is associated with explosive hazards related to its strong oxidizing power. In this study, we examined hydrochloric acid as an alternative dissolution medium. The precipitated material was a nanopowder of chlorapatite $\left(\mathrm{Ca}_{10}\left(\mathrm{PO}_{4}\right)_{6} \mathrm{Cl}_{2}\right)$, whose reactivity is lower than hydroxyapatite due to the key role of $\mathrm{OH}^{-}$in its surface properties. Topotactic, i.e. shape preserving, conversion of chlorapatite and other phosphocalcic apatite into hydroxyapatite has already been described in hydrothermal conditions from well-crystallized powders $[24,25]$. These approaches required strong alkalinity $(\mathrm{KOH}, 6.25 \mathrm{M})$, high temperatures (> 
$300{ }^{\circ} \mathrm{C}$ ) and relatively long reaction times (> $\left.12 \mathrm{~h}\right)$ but allowed for conversion of large crystals (several mm). Alternatively, for nanoscale particles with high interfacial reactivity and easy dispersion, topotactic transformations of calcium phosphates using ultrasound irradiation appears as a suitable and fast method [26,27]. On this basis, the effect of sonication on the topotactic transformation of chloroapatite nanocrystals into hydroxyapatite was demonstrated and the mechanisms by which the conversion can be influenced by ultrasound irradiation are discussed. In particular, the key role of undersatured conditions on the ultrasound-induced transformation is evidenced. These results demonstrate that the structural conversion can be achieved without particle amorphization but with size reduction, offering a simple and original method to obtain hydroxyapatite nanoparticles with tailored crystallinity and dimensions.

\section{Materials and methods}

\subsection{Materials}

The phosphate rock sample used was from the Bengurir region (Morocco). The sample was washed and then sieved to give a $-400 /+100 \mu \mathrm{m}$ size fraction using ASTM Standard sieves, this grain size being optimum for efficient dissolution. As reported earlier [4], it consists of a mixture of francolite and quartz $(2.5 \mathrm{wt} \%)$ and its composition in major mineral elements is provided in Table 1.

\subsection{Synthesis}

The conversion of the natural ore into nanosized powders was performed according to a previously described procedure [23]. Dissolution of the phosphate rock was carried out in a 1 L open glass reactor with a spherical bottom at a rate of $200 \mathrm{rpm}$. For each experiment, the temperature was set to $25^{\circ} \mathrm{C}$. The phosphate rock $(20 \mathrm{~g})$ was first dissolved in $80 \mathrm{~mL}$ of deionized water supplemented with $20 \mathrm{~mL}$ of concentrated hydrochloric acid (37\%) or nitric 
acid $(65 \%)$ to obtain the solvated $\mathrm{Ca}^{2+}$ and hydrogenophosphate species. Insoluble matter, mainly quartz, was then separated by filtration. The remaining solution was neutralized using $100 \mathrm{~mL}$ of a concentrated $\mathrm{NH}_{4} \mathrm{OH}$ solution $(25 \%)$. The $\mathrm{pH}$ value of the precipitation reaction was maintained at $\mathrm{pH} 10$ to avoid the formation of other non-apatitic calcium phosphates. The resulting powder was recovered by filtration and either washed several times with deionized water or re-dispersed in $100 \mathrm{~mL}$ deionized water under stirring for $30 \mathrm{~min}$ and then placed in an ultrasonic water bath $(200 \mathrm{~W}, 35 \mathrm{kHz})$ for 1 hour. The resulting products were recovered by filtration and thoroughly washed with water. Both set of samples were dried overnight at $100^{\circ} \mathrm{C}$. The precipitated samples are noted $\mathrm{Cl}-\mathrm{CP}$ and $\mathrm{N}-\mathrm{CP}$ according to the inorganic acid $\left(\mathrm{HCl}\right.$ and $\left.\mathrm{HNO}_{3}\right)$ used for dissolution; uCl-CP and $\mathrm{uN}-\mathrm{CP}$ correspond to the powders obtained from sonication. Further heating of the samples was performed at $800^{\circ} \mathrm{C}$. The overall flow diagram of the process is summarized in Figure 1.

2.3. Characterization. The crystalline phases were identified using a powder X-ray diffractometer (XRD) (Philips PW131 diffractometer) using the $\mathrm{CuK} \alpha$ radiation. Infrared spectra were recorded from $400 \mathrm{~cm}^{-1}$ to $4000 \mathrm{~cm}-1$ on a Bruker IFS 66v Fourier transform spectrometer using $\mathrm{KBr}$ pellets. Particles were imaged using Transmission Electron Microscopy (TEM) on a TECNAÏ G2 instrument. Calcium and phosphorus content of the powders were determined by inductively coupled plasma atomic emission spectroscopy (ICPAES) (ICPS-7500, Shimadzu, Japan). Chloride content was determined using the Mohr method. The $\mathrm{N}_{2}$ adsorption-desorption isotherms for dried powders were obtained by multipoint $\mathrm{N}_{2}$-gas adsorption-desorption experiments at $77 \mathrm{~K}$ using a Micromeritics ASAP 2010 instrument. The specific surface areas were calculated according to the Brunauer-EmmettTeller (BET) method using adsorption data in the relative pressure range from 0.05 to 0.25 whereas the pore size and volume were estimated using the Barret-Joyner-Halenda (BJH) approximation. 


\section{Results}

The X-Ray diffractograms of non-sonicated Cl-CP and $\mathrm{N}-\mathrm{CP}$ dried at $100^{\circ} \mathrm{C}$ and heated at $800^{\circ} \mathrm{C}$ are shown in Figure $2 \mathrm{a}$. The dried $\mathrm{Cl}-\mathrm{CP}$ and $\mathrm{N}-\mathrm{CP}$ samples exhibit a series of very similar low intensity peaks but differ from a multi-component signal in the $2 \theta=31-34^{\circ}$ range for the former and $32-35^{\circ}$ domain for the latter. After heating at $800^{\circ} \mathrm{C}$ much narrower diffraction peaks are obtained allowing for complete resolution of these complex signals (Figure 2c,d). The replacement of $\mathrm{OH}^{-}$ions in hydroxyapatite $\mathrm{Ca}_{10}\left(\mathrm{PO}_{4}\right)_{6}(\mathrm{OH})_{2}(\mathrm{HAp})$ by $\mathrm{Cl}^{-}$ in chloroapatite $\mathrm{Ca}_{10}\left(\mathrm{PO}_{4}\right)_{6}(\mathrm{Cl})_{2} \quad(\mathrm{ClAp})$ was reported to result in an increase of the $a$ parameter (from $9.418 \AA$ to $9.641 \AA$ ) and decrease in $c$ parameter (from $6.884 \AA$ to $6.771 \AA$ ) of the apatite structure [24]. These variations can easily be visualized by the shift of the (211) diffraction peak shift from $31.8^{\circ}$ to $31.3^{\circ}$ and the (300) from $32.8^{\circ}$ to $32.3^{\circ}$. The (112) peak that is clearly evidenced for HAp at $32.2^{\circ}$ is shifted to $32.4^{\circ}$ in ClAp, becoming merged with the (300) (Figure 2b). Altogether, it is possible to assume that N-CP sample consists of HAp and $\mathrm{Cl}-\mathrm{CP}$ of ClAp although the presence of minor amounts of HAp in the later cannot be fully excluded. As a comparison, sonicated samples obtained from natural phosphate dissolution in $\mathrm{HCl}$ ( $\mathrm{uCl}-\mathrm{CP}$ ) and $\mathrm{HNO}_{3}$ (uN-CP) showed only diffraction peaks corresponding to the HAp structure (Figure $2 \mathrm{~b}$ ). The only noticeable difference is the lower resolution of the $32-35^{\circ}$ broad diffraction signal for $\mathrm{uCl}-\mathrm{CP}$ at $100^{\circ} \mathrm{C}$ compared to $\mathrm{uN}-\mathrm{CP}$ at the same temperature, indicative of its lower crystallinity. Importantly, no significant difference was observed between N-CP and $\mathrm{uN}-\mathrm{CP}$ after drying.

Elemental analysis of the samples shows that the Cl-CP sample contains ca. $6 \%$ of $\mathrm{Cl}$ (Table 2). The theoretical atomic $\%$ of $\mathrm{Cl}$ for the chloroapatite formula is $6.9 \%$, allowing to estimate that the powder is a mixture of $85 \% \mathrm{ClAp}$ and $15 \% \mathrm{HAp}$. The $\mathrm{Cl}$ amount decreased to $0.05 \%$ for $\mathrm{uCl}-\mathrm{CP}$, corresponding to less than $5 \mathrm{wt} \%$ remaining $\mathrm{ClAp}$ or formation of a 
chloride substituted hydroxyapatite $\mathrm{Ca}_{10}\left(\mathrm{PO}_{4}\right)_{6} \mathrm{Cl}_{2 x}(\mathrm{OH})_{2(1-x)}$ with $x \approx 0.007$. As far as the $\mathrm{Ca} / \mathrm{P}$ ratio is concerned, it is found superior than the stoichiometric ratio 1.67 of pure HAp and ClAp, supporting the formation of carbonated apatites. However, a decrease in the $\mathrm{Ca} / \mathrm{P}$ ratio is observed after sonication for both $\mathrm{HCl}$ - and $\mathrm{HNO}_{3}$-treated samples, suggesting that the degree of carbonatation is smaller after irradiation.

FTIR spectra of selected samples are shown in Figure 3. For dried powders, the main difference between the $\mathrm{Cl}-\mathrm{CP}$ and $\mathrm{uCl}-\mathrm{CP}$ samples is the vibration band at $3560 \mathrm{~cm}^{-1}$ corresponding to $\mathrm{OH}$ groups of the HAp structure that is evidenced only in the $\mathrm{uCl}-\mathrm{CP}$ spectra. This difference is even more clearly visible on the $800^{\circ} \mathrm{C}$-heated samples, where the corresponding band is more easily visible for $\mathrm{uCl}-\mathrm{CP}$ due to the decrease of the broad band attributed to the vibration of bound water. This is in agreement with the substitution of $\mathrm{Cl}^{-}$by $\mathrm{OH}^{-}$during the sonication process. Noticeably, at this temperature, $\mathrm{uCl}-\mathrm{CP}$ and $\mathrm{N}-\mathrm{CP}$ are almost undistinguishable, in agreement with XRD data. The vibration bands in the 1020-1100 $\mathrm{cm}^{-1}$ wavenumber range that correspond to $\mathrm{PO}_{4}$ groups show a strong tendency to saturate for $\mathrm{N}-\mathrm{CP}$ and $\mathrm{uCl}-\mathrm{CP}$ at $800^{\circ} \mathrm{C}$, in agreement with high degree of crystallinity of the HAp phase. At the same temperature, this band is broader for $\mathrm{Cl}-\mathrm{CP}$, reflecting the coexistence of HAp and ClAp phases in the powder. FTIR spectra of dried powders showed additional bands near $1450 \mathrm{~cm}^{-1}$ and $1650 \mathrm{~cm}^{-1}$ that almost disappear from the spectra of the heated samples. The former corresponds to carbonate ions incorporated in the apatite structure while the latter indicates adsorbed water molecules, both of which should be withdrawn from the apatite after dehydration and decarbonation.

TEM images of the dried powders are shown in Figure 4. $\mathrm{Cl}-\mathrm{CP}$ and $\mathrm{uCl}-\mathrm{CP}$ samples consist of well-defined nanoparticles of similar morphologies but different lengths, i.e. $42 \pm 6$ $\mathrm{nm}$ for $\mathrm{Cl}-\mathrm{CP}$ compared to $19 \pm 5 \mathrm{~nm}$ for uCl-CP. As a comparison, $\mathrm{N}-\mathrm{CP}$ and $\mathrm{uN}-\mathrm{CP}$ 
powders consist of similar particles although with an apparent lower aspect ratio compared to $\mathrm{HCl}$-precipitated samples. Particle length obtained from TEM image was $29 \pm 3 \mathrm{~nm}$ for N-CP and $16 \pm 3 \mathrm{~nm}$ for $\mathrm{uN}-\mathrm{CP}$.

After heating, all samples consisted of densely-packed aggregates or fused nanoparticles with various morphologies (Figure 5). Although a precise measurement of particle size is difficult from such TEM images, $\mathrm{Cl}-\mathrm{CP}$ and $\mathrm{uCl}-\mathrm{CP}$ give average diameter of $51 \pm 11 \mathrm{~nm}$ and $44 \pm 8 \mathrm{~nm}$, respectively, whereas $\mathrm{N}-\mathrm{CP}$ and $\mathrm{uN}-\mathrm{CP}$ gives $70 \pm 8 \mathrm{~nm}$ and $58 \pm 8 \mathrm{~nm}$ respectively. This suggests that the initial size difference between sonicated and unsonicated samples is preserved upon heating, at least to some extent.

Nitrogen sorption isotherms of dried powders are gathered in Figure 6 and indicate that all powders are mesoporous. Specific surface area calculated using the BET model $\left(S_{B E T}\right)$ show that $\mathrm{Cl}-\mathrm{CP}$ has the smallest value while $\mathrm{uCl}-\mathrm{CP}$ and $\mathrm{uN}-\mathrm{CP}$ have the highest, with $\mathrm{N}-\mathrm{CP}$ being intermediate (Table 2). Although calculation of porous volume ( $V p)$ and average pore size $(D p)$ of powders must be taken cautiously due to particle displacement during nitrogen filling, estimated values indicate close $V p$ values for all powders and significant variations in $D p$. This means that the density of each powder is similar but that the difference in accessible surface is due to a variation in pore size. The obtained values are in good agreement with TEM imaging as the values of calculated $S_{B E T}$ follow the same trend as particle size evolution. This supports the assumption that the measured mesoporosity does not originate from the internal structure of the particles but from interparticle spacings in the powder form.

\section{DISCUSSION}

The full dissolution of $20 \mathrm{~g}$ of the natural phosphate in $100 \mathrm{~mL}$ of a $2.4 \mathrm{M} \mathrm{HCl}$ solution leads to final concentrations of $\left[\mathrm{Ca}^{2+}\right]=2 \mathrm{M},\left[" \mathrm{PO}_{4} "\right]=1.2 \mathrm{M}$ and $\left[\mathrm{Cl}^{-}\right]=2.4 \mathrm{M}$, where [" $\mathrm{PO}_{4}$ "] represent the total phosphate content, i.e. $\mathrm{H}_{\mathrm{x}} \mathrm{PO}_{4}{ }^{3-\mathrm{x}}$ species. Increasing the $\mathrm{pH}$ to 10 
by adding $100 \mathrm{~mL} \mathrm{NH} \mathrm{NH}_{4} \mathrm{OH}$ leads to $\left[\mathrm{OH}^{-}\right]=10^{-4} \mathrm{M},\left[\mathrm{Ca}^{2+}\right]=1 \mathrm{M},\left[" \mathrm{PO}_{4}\right.$ "] $]=6.10^{-1} \mathrm{M}^{2}$ and $\mathrm{Cl}^{-}$ $=1.2 \mathrm{M}$. The reaction of chlorapatite formation is (eq. 1) [28]

$$
10 \mathrm{Ca}^{2+}+6 \mathrm{PO}_{4}^{3-}+2 \mathrm{Cl}^{-} \Leftrightarrow \mathrm{Ca}_{10}\left(\mathrm{PO}_{4}\right)_{6} \mathrm{Cl}_{2}
$$

with a solubility constant $K_{S C}$ at $25^{\circ} \mathrm{C}$ of $10^{-115}$

The reaction of hydroxyapatite formation is (eq. 2)

$10 \mathrm{Ca}^{2+}+6 \mathrm{PO}_{4}^{3-}+2 \mathrm{OH}^{-} \Leftrightarrow \mathrm{Ca}_{10}\left(\mathrm{PO}_{4}\right)_{6}(\mathrm{OH})_{2}$

with a solubility constant $K_{S H}$ at $25^{\circ} \mathrm{C}$ of $10^{-110}$

The ionic products $I P$ relevant for ClAp and HAp formation in the conditions of the experiments are

$$
\begin{aligned}
& I P_{C}=\left[\mathrm{Ca}^{2+}\right]^{10}\left[\mathrm{PO}_{4}^{3-}\right]^{6}\left[\mathrm{Cl}^{-}\right]^{2}=6.710^{-2} \\
& I P_{H}=\left[\mathrm{Ca}^{2+}\right]^{10}\left[\mathrm{PO}_{4}^{3-}\right]^{6}\left[\mathrm{OH}^{-}\right]^{2}=4.610^{-10}
\end{aligned}
$$

Supersaturation $S$, calculated as the ratio between the ionic product and solubility constant $I P / K$, is therefore $S_{C}=10^{+113}$ and $S_{H}={ }^{+100}$ for ClAp and HAp, respectively. The free enthalpy of the reaction of precipitation can be written as (eq. 5)

$$
\Delta G_{r}=-\mathrm{RT} \ln S
$$

Since $S_{C}$ and $S_{H}>1$ and $S_{C}>S_{H}$, the free enthalpy values are negative for ClAp and HAp, indicating that the two reactions are spontaneous, with ClAp precipitation being thermodynamically favored compared to HAp formation

After resuspension in deionized water $(\mathrm{pH} 7),\left[\mathrm{Cl}^{-}\right]$is negligible, shifting the equilibrium (1) towards dissolution, releasing $\mathrm{Ca}^{2+}$ and $\mathrm{PO}_{4}{ }^{3-}$ with $10\left[\mathrm{Ca}^{2+}\right]=6\left[\mathrm{PO}_{4}^{3-}\right]$. In these conditions, $S_{H}>1$, i.e. HAp can reprecipitate, as soon as $\left[\mathrm{Ca}^{2+}\right]>10^{-6} \mathrm{M}$. This is to be compared with the calcium concentration in the resuspension (2 M), suggesting that, despite initial undersaturated ionic conditions, as soon as chlorapatite particles start to dissolve, reprecipitation of HAp can occur (Figure 7a). It is worth pointing out that the conversion of ClAp micron-size single crystals into HAp in high temperature $\left(>1000^{\circ} \mathrm{C}\right)$ conditions was 
reported to occur via an ion-exchange mechanism [29]. The contribution of such an ionexchange reaction in our working conditions cannot be put aside but the observed accompanying erosion process (vide infra) strongly support that dissolution/reprecipitation mechanisms are prevalent.

Such a crystallographic conversion is associated with a preservation of the morphology of the particles but with a decrease in size from $\mathrm{Cl}-\mathrm{CP}$ to uCl-CP. However, a decrease of particle dimension is also observed with pure HAp particles prepared using $\mathrm{HNO}_{3}$ after a similar ultrasound treatment. Several previous reports have demonstrated the ability of ultrasound to tune HAp particle size but these studies were devoted to particle growth from $\mathrm{Ca}^{2+}$ and phosphate salts [13-21] and often describes a continuous process occurring from an amorphous calcium phosphate phase to crystalline HAp. In these works, decrease of particle size upon irradiation was attributed to the formation of hot spots resulting from cavitation bubbles collapse that favor nucleation events. One recent report also describes the sonicationinduced conversion of brushite $\mathrm{CaHPO}_{4} \cdot 2 \mathrm{H}_{2} \mathrm{O}$ into monocalcium phosphate monohydrate $\mathrm{Ca}\left(\mathrm{H}_{2} \mathrm{PO}_{4}\right)_{2} \cdot \mathrm{H}_{2} \mathrm{O}$ via monetite $\mathrm{CaHPO}_{4}$ formation [26]. These transformations are possible due to the increasing stability of the successive phases but can be favored by the cavitation phenomenon that enhances exchange reactions occurring at the particle surface, especially dehydration that leads to a local increase in supersaturation [30]. The other key effect of ultrasound irradiation is related to its ability to limit particle aggregation [16].

These two effects can be conjointly involved in the here-described process. On the one hand, ultrasound irradiation allows for an efficient dispersion of the particles, not only in the initial solution but also during the phase transformation where the high reactivity of the colloidal surfaces should confer them a strong tendency to aggregate. On the other hand, the supersaturation at the particle vicinity due to efficient surface dissolution should enhance the kinetics of the exchange of $\mathrm{Cl}^{-}$by $\mathrm{OH}^{-}$. However it is important to point out that this 
exchange is thermodynamically-favorable reaction, a fact that can explain that the use of a lower ultrasound irradiation power $(160 \mathrm{~W})$ did not significantly modify the size and structure of the recovered uCl-CP nanoparticles (data not shown).

It is interesting to note that we found no clear evidence of the amorphization of the CP particles upon sonication, contrasting from previous reports [21], but rather a decrease in particle size. This can be explained considering that the previous observations were obtained for particles in their mother liquor, i.e. at the solubility limit for the bulk liquid. In this case, the chemical equilibrium between hydroxyapatite and its constituting ions was towards the precipitation process so that the amorphous phase remains in a solid form (Figure $7 \mathrm{~b}$ ). In contrast, in the present work, the sonication process is performed in a salt-free solution so that surface erosion via dissolution and ion release becomes possible (Figure 7c).

Finally, the question is raised about the impact of the ultrasound irradiation of the chemical properties of the HAp nanoparticles. It has been previously shown that the erosion process enhanced the surface reactivity of metal nanoparticles as it allowed for the removal of the external metal oxide layer [31]. In contrast, for hydroxyapatite, it is well-known that the bulk phase is relatively inert [32] whereas the presence of a disordered outer layer makes its surface more reactive [33]. However, the generation of $\mathrm{OH}^{-}$radical species upon water irradiation may impact on the particle surface composition and structure [34]. Therefore a more detailed study of the surface reactivity of these nanoparticles is required to fully understand the influence of ultrasonication on their reactivity

\section{Conclusions}

This work demonstrates that sonication provides a simple and fast method to achieve the topotactic conversion of chlorapatite into hydroxyapatite at the nanoscale. Such a conversion is made possible by the redispersion of the chlorapatite suspension in deionized water, 
allowing for the favorable exchange between $\mathrm{Cl}^{-}$and $\mathrm{OH}^{-}$. These conditions also favor erosion over amorphization, therefore providing a method to tailor hydroxyapatite particle size without impacting on its crystallinity, an original route that must be explored further.

\section{ACKNOWLEDGMENTS}

This work was funded by the PICS APATENV program of CNRS (France) and CNRST (Marocco). The authors thank P. Le Griel (LCMCP) for assistance in TEM observations. 


\section{REFERENCES}

[1] P. Becker. Phosphates and Phosphoric Acid: Raw Materials, Technology, and Economics of the Wet Process, Marcel Dekker, New York (1983)

[2] E.M. Banane, J. Bahraoui-Buret, L. Belkbir, G. Flamant The kinetics of the thermal decomposition of natural moroccan and iraqi phosphates, Thermochim. Acta 152 (1989) 115123

[3] A. Aouad, M. Benchanâa, A. Mokhlisse and A. Ounas, Thermal analysis of Moroccan phosphates "Youssoufia" in an oxidative atmosphere by TG and DSC, J. Therm. Anal. Calorim. 75 (2004) 887-900.

[4] S. El Asri, A. Laghzizil, A. Saoiabi, A. Alaoui, A. Saoiabi, R. M’Hamdi, K. El Abbassi and A. Hakam, Structure and thermal behaviors of Moroccan phosphate rock (Bengurir), J. Therm. Anal. Calorim. 95 (2009) 15-19.

[5] Q.Y. Ma, S.J. Traina, T.J. Logan, J.A. Ryan, In situ lead immobilization by apatite, Environ. Sci. Technol. 27 (1993) 1803-1810.

[6] A. Dybowska, D.A.C. Manning, M.J. Collins, T. Wess, S. Woodgate, E. Valsami-Jones, An evaluation of the reactivity of synthetic and natural apatites in the presence of aqueous metals, Sci. Tot. Environ. 407 (2009) 2953-2965.

[7] A. Nzihou, P. Sharrock, Role of phosphate in the remediation and reuse of heavy metal polluted wastes and sites, Waste Biomass. Valor. 1 (2010) 163-174.

[8] H. Bouyarmane, S. El Asri, A. Rami, C. Roux, M.A. Mahly, A. Saoiabi, T. Coradin, A. Laghzizil, Pyridine and phenol removal using natural and synthetic apatites as low cost 
sorbents: Influence of porosity and surface interactions, J. Hazard. Mater. 181 (2010) 736741.

[9] A. Aklil, M. Mouflih, S. Sebti, Removal of heavy metal ions from water by using calcined phosphate as a new adsorbent, J. Hazard. Mater. A112 (2004) 183-190.

[10] C. Xinde, Q. Ma-Lena, R. R. Dean, S. A. Chip, Mechanisms of lead, copper, and zinc retention by phosphate rock, Environ. Pollut. 131 (2004) 435-444.

[11] A. Bahdod, S. El Asri, A. Saoiabi, T. Coradin, A. Laghzizil, Adsorption of phenol from an aqueous solution by selected apatite adsorbents : kinetic process and impact of the surface properties, Water Res. 43 (2009), 313-318

[12] S.V. Dorozhkin, Nanodimensional and Nanocrystalline Apatites and Other Calcium Orthophosphates in Biomedical Engineering, Biology and Medicine, Materials 2 (2009) $1975-2045$

[13] W. Kim, F. Saito, Sonochemical synthesis of hydroxylapatite from $\mathrm{H}_{3} \mathrm{PO}_{4}$ solution with $\mathrm{Ca}(\mathrm{OH})_{2}$, Ultrason. Sonochem. 8 (2001) 65-88.

[14] M. de Campos, F.A. Müller, A.H. Bressiani, J.C. Bressiani, P. Greil, Sonochemical synthesis of calcium phosphate powders J. Mater. Sci.: Mater. Med. 18 (2007) 669-675.

[15] M. Jevtic, M. Mitric, S. Skapin, B. Jancar, N. Ignjatovic, D. Uskokovic, Crystal structure of hydroxyapatite nanorods synthesized by sonochemical homogeneous precipitation, Cryst. Growth Des. 8, 2008, 2217-2222.

[16] G.E. Poinern, R.K. Brundavanam, N. Mondinos, Z.-T. Jiang, Synthesis and characterisation of nanohydroxyapatite using an ultrasound assisted method, Ultrason. Sonochem. 16 (2009) 469-474

[17] P. Rouhani, N. Taghavinia, S. Rouhani, Rapid growth of hydroxyapatite nanoparticles using ultrasonic irradiation, Ultrason. Sonochem. 17 (2010) 853-856.

[18] Z. Zou, K. Lin, L. Chen, J. Chang, Ultrafast synthesis and characterization of 
carbonated hydroxyapatite nanopowders via sonochemistry-assisted microwave process, Ultrason. Sonochem.19 (2012) 1174-1179.

[19] Y. Kojima, K. Kitazawa, N. Nishimiya, Synthesis of nano-sized hydroxyapatite by ultrasound irradiation, J. Phys.: Conf. Ser. 339 (2012) 012001.

[20] N. Varadarajan, R. Balu, D. Rana, M. Ramalingam, T.S. Kumar, Accelerated sonochemical synthesis of calcium deficient hydroxyapatite nanoparticles: structural and morphological evolution, J. Biomater. Tissue Engin. 4 (2014) 295-299.

[21] K. He, G.-Y. Xiao, W.-H. Xu, R.-F. Zhu, Y.-P. Lu, Ultrasonic enhancing amorphization during synthesis of calcium phosphate, Ultrason. Sonochem. 21 (2014) 499-504.

[22] S. El Asri, A. Laghzizil, T. Coradin, A. Saoiabi, A. Alaoui, R. M'hamdi, Conversion of natural phosphate rock into mesoporous hydroxyapatite for heavy metals removal from S. E1 [23] S. El Asri, A. Laghzizil, A. Saoiabi, K. El Abassi, R. M'hamdi T. Coradin, A novel process for the fabrication of nanoporous apatites from Moroccan phosphate rock, Colloid Surf. A: Physicochem. Eng. Aspects 350 (209) 73-78.

[24] K. Yanagisawa, J.C. Rendon-Angeles, N. Ishizawa, S. Oishi, Topotaxial replacement of chlorapatite by hydroxyapatite during hydrothermal ion exchange, American Mineralogist, 84 (1999) 1861-1869.

[25] J.C. Rendon-Angeles, K. Yanagisawa, N. Ishizawa, S. Oishi, Effect of metal ions of chloroapatites on the topotaxial replacement by hydroxyapatite under hydrothermal conditions, J. Solid State Chem. 154 (2000) 569-578.

[26] J. Sánchez-Enríquez, J. Reyes-Gasga, Obtaining $\mathrm{Ca}\left(\mathrm{H}_{2} \mathrm{PO}_{4}\right)_{2} \cdot \mathrm{H}_{2} \mathrm{O}$, monocalcium phosphate monohydrate, via monetite from brushite by using sonication, Ultrason. Sonochem. 20 (2013) 948-954. 
[27] M. Wang, J. Gao, C. Shi, Y. Zhu, Y. Zeng, D. Wang, Facile one-pot synthesis of oriented pure hydroxyapatite with hierarchical architecture by topotactic conversion, Cryst. Growth Des. 14 (2014) 6459-6466.

[28] T.N.B Narasaraju, K.K. Rao, U.S. Rai, Determination of solubility products of hydroxylapatite, chlorapatite, and their solid solutions, Can. J. Chem. 57 (1979) 1919-1922.

[29] E. Garcia-Tuñon, B. Dacuña, G. Zaragoza, J. Franco, F. Guitiàn, Cl-OH ion-exchanging process in chlorapatite $\left(\mathrm{Ca}_{5}\left(\mathrm{PO}_{4}\right)_{3} \mathrm{Cl}_{x}(\mathrm{OH})_{1-x}\right)$ - a deep insight, Acta Cryst. B68, 2012, 467479.

[30] M.C. Barbosa, N.R. Messmer, T.R. Brazil, F.R. Marciano, A.O. Lobo, The effect of ultrasonic irradiation on the crystallinity of nano-hydroxyapatite produced via the wet chemical method, Mater. Sci. Engin. C Mater. Biol. Appl. 33 (2013) 2620-2625.

[31] K.S. Suslick, The chemical effects of ultrasound, Sci. Am. 260 (1989) 80-86

[32] D. Zahn, O. Hochrein, Computational study of interfaces between hydroxyapatite and water, Phys. Chem. Chem. Phys. 5 (2003) 4004-4007

[33] P.W. Brown, R.I. Martin, An analysis of hydroxyapatite surface layer formation, J. Phys. Chem. B 103 (1999) 1671-1675

[34] K. Makino, M.M. Mossoba, P. Riesz, Chemical effects of ultrasound on aqueous solutions. Formation of hydroxyl radicals and hydrogen atoms, J. Phys. Chem. 87 (1983) $1369-1377$ 
Table 1. Chemical analysis of the phosphate rock used in this study [4].

\begin{tabular}{llllll}
\hline$\% \mathrm{Ca}$ & $\% \mathrm{P}$ & $\% \mathrm{~F}$ & $\% \mathrm{Si}$ & $\% \mathrm{~S}$ & $\% \mathrm{Na}$ \\
& & & & & \\
\hline 37.84 & 15.03 & 2.84 & 1.78 & 0.78 & 0.79 \\
& & & & & \\
\hline
\end{tabular}


Table 2. Elemental analyses, specific surface area $\left(S_{B E T}\right)$, porous volume $\left(V_{p}\right)$ and average pore diameter $\left(D_{p}\right)$ for dried powders obtained from conversion of natural phosphates before and after ultrasound treatment.

\begin{tabular}{llllllll}
\hline Sample & $\% \mathrm{Ca}$ & $\% \mathrm{P}$ & $\% \mathrm{Cl}$ & $\mathrm{Ca} / \mathrm{P}$ & $\begin{array}{l}S_{B E T} \\
\left(\mathrm{~m}^{2} \cdot \mathrm{g}^{-1}\right)\end{array}$ & $\begin{array}{l}V_{p} \\
\left(\mathrm{~cm}^{3} \cdot \mathrm{g}^{-1}\right)\end{array}$ & $(\mathrm{nm})$ \\
\hline $\mathrm{uCl}-\mathrm{CP}$ & 37.55 & 16.78 & 0.05 & 1.73 & 165 & 0.36 & 7.0 \\
$\mathrm{Cl-CP}$ & 37.01 & 15.85 & 5.99 & 1.80 & 120 & 0.37 & 10.8 \\
$\mathrm{uN}-\mathrm{CP}$ & 38.05 & 15.52 & $<0.01$ & 1.89 & 160 & 0.38 & 9.0 \\
$\mathrm{~N}-\mathrm{CP}$ & 38.66 & 15.33 & $<0.01$ & 1.95 & 150 & 0.39 & 11.5 \\
\hline
\end{tabular}




\section{Figure captions}

Figure 1. Flow diagram of the preparation of nanosized apatite samples

Figure 2. XRD patterns of the dried and $800^{\circ} \mathrm{C}$-heated powders $(\mathrm{a}, \mathrm{b})$ before and $(\mathrm{c}, \mathrm{d})$ after ultrasound irradiation. $(\mathrm{OH})$ and $\mathrm{Cl}$ correspond to hydroxyapatite and chloroapatite structures, respectively

Figure 3. FTIR spectra of selected powder samples.

Figure 4. TEM images of the dried powders before and after ultrasound irradiation: (a) Cl$\mathrm{CP},(\mathrm{b}) \mathrm{uCl}-\mathrm{CP},(\mathrm{c}) \mathrm{N}-\mathrm{CP}$ and (d) uN-CP (scale bar $=20 \mathrm{~nm}$ ).

Figure. 5. TEM images of the $800^{\circ} \mathrm{C}$-heated powders before and after ultrasound irradiation: (a) Cl-CP, (b) uCl-CP, (c) N-CP and (d) uN-CP (scale bar = $20 \mathrm{~nm}$ ).

Figure 6. $\mathrm{N}_{2}$-Sorption isotherms of the dried powders before and after ultrasound irradiation

Figure 7. Possible effect of ultrasound irradition (US) on (a) chlorapatite nanocrystals (green) in water, leading to dissolution, erosion and reprecipitation of hydroxyapatite (light blue), (b) hydroxyapatite nanocrystals in mother liquor, leading to dissolution and reprecipitation of hydroxyapatite (dark blue), (c) hydroxyapatite nanocrystals in water, leading to dissolution and erosion. 
Figure 1

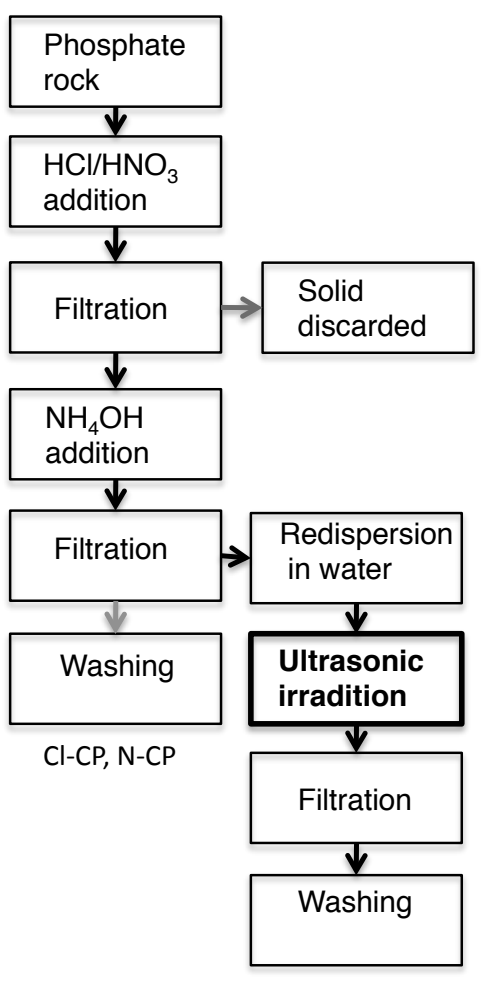

uCl-CP, uN-CP 
Figure 2
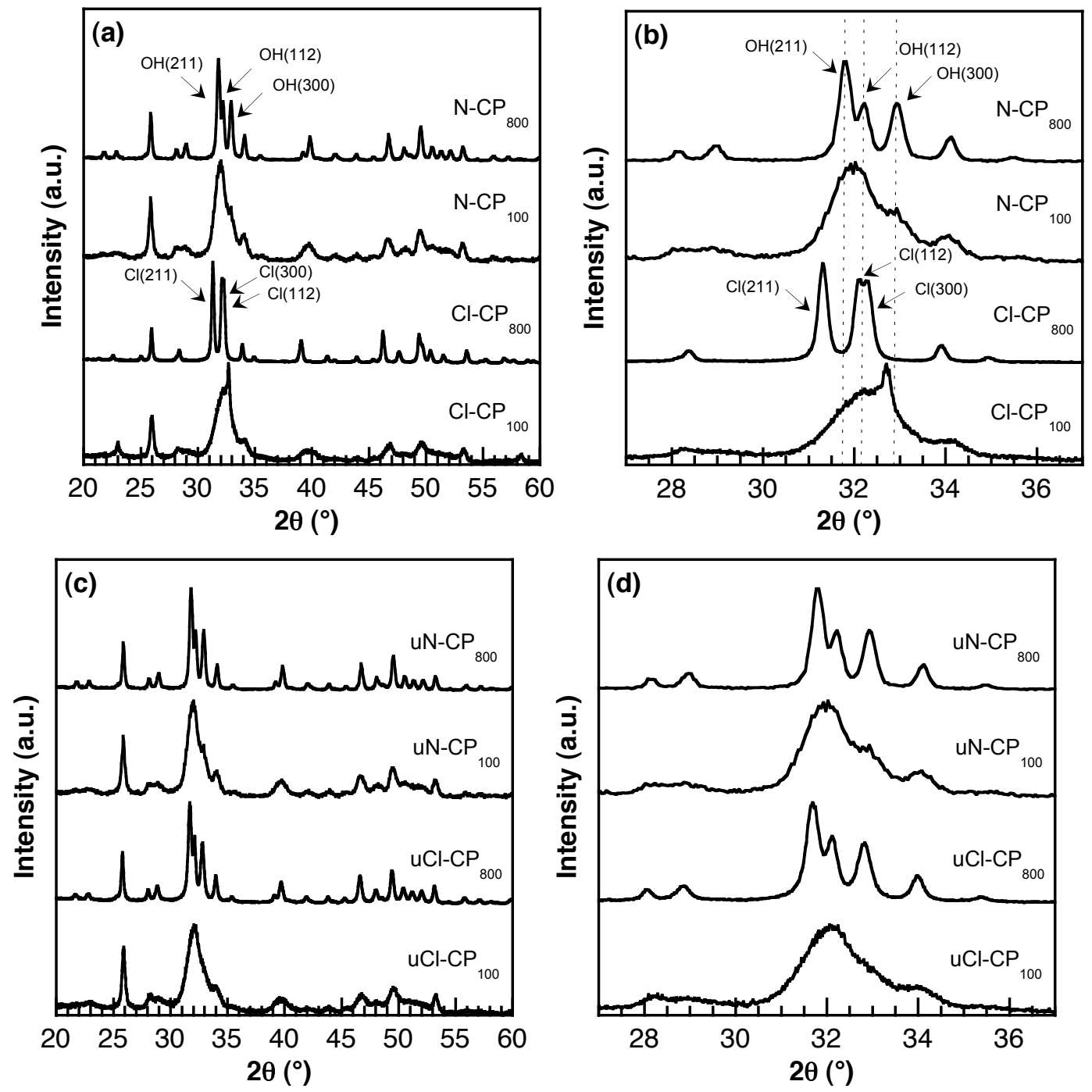
Figure 3

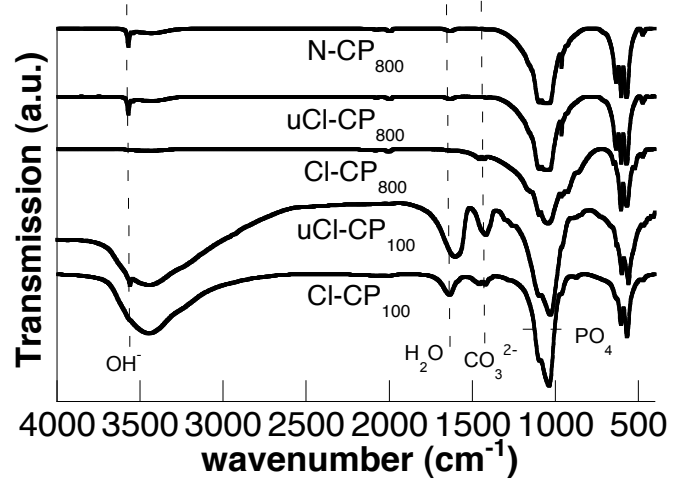


Figure 4

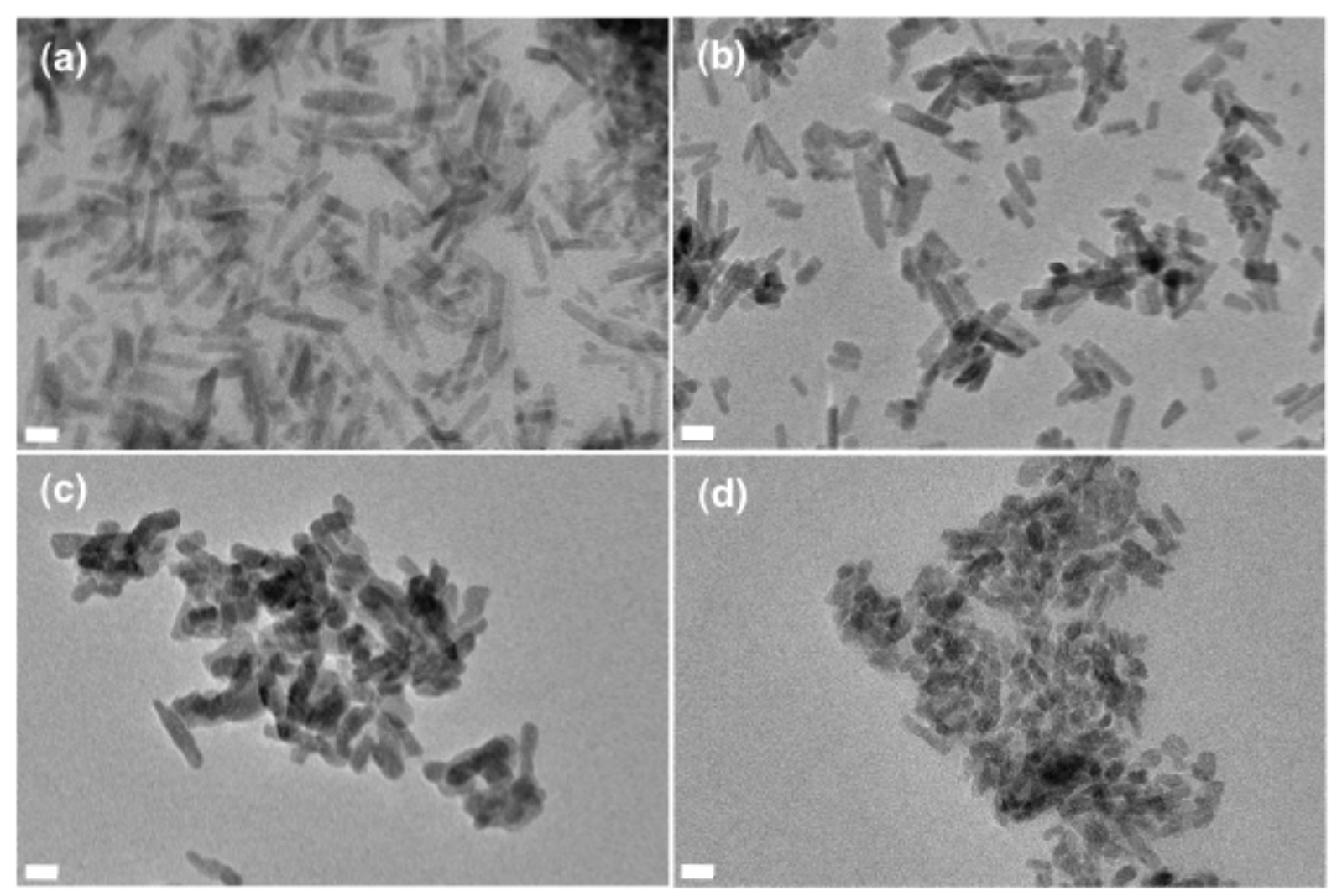


Figure 5

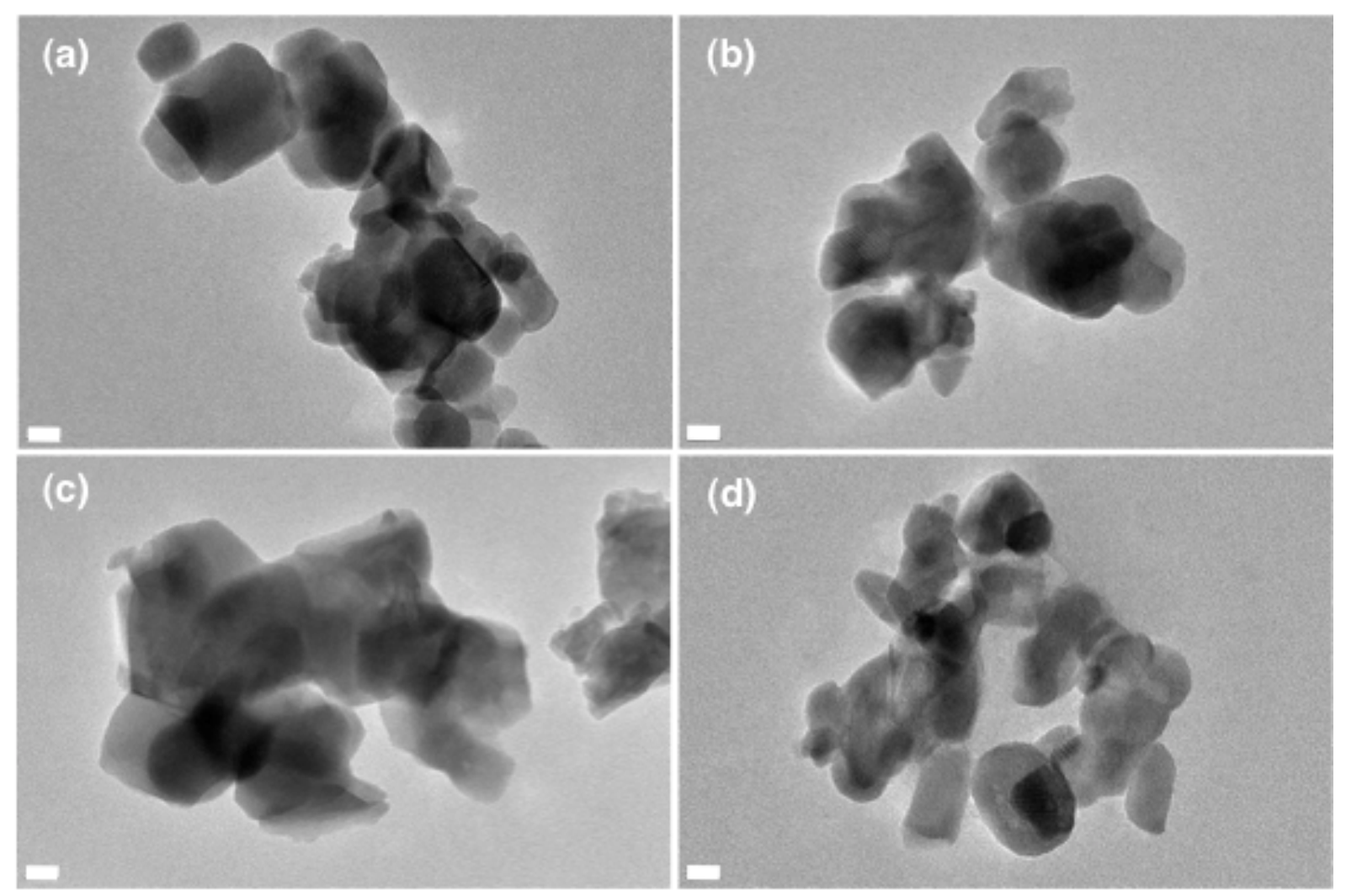


Figure 6

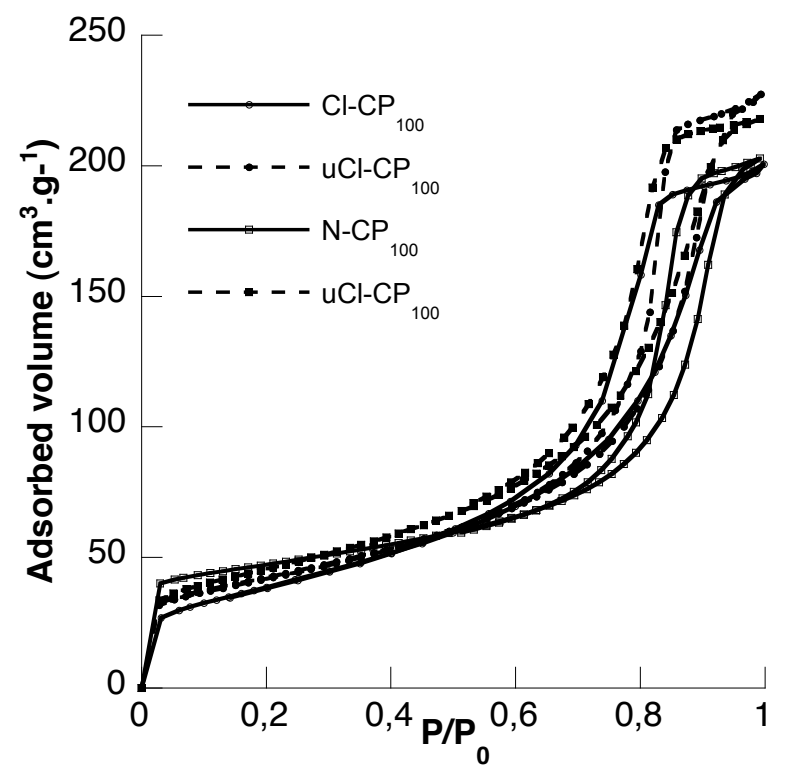


Figure 7

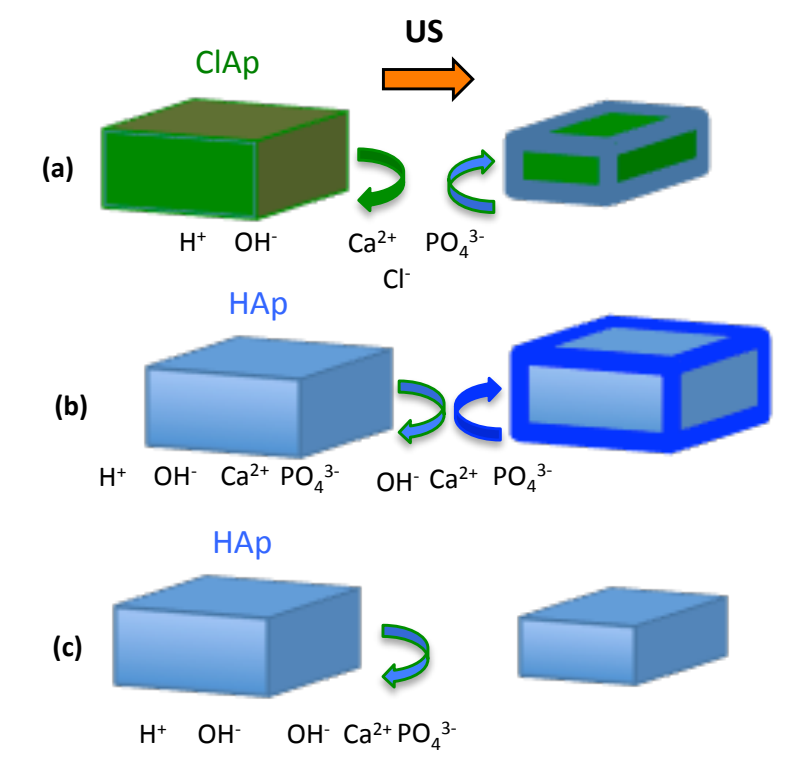

